\section{DIGITAL COMMONS \\ @ UNIVERSITY OF SOUTH FLORIDA}

\section{ABO: Interactive Journal for Women in the Arts, 1640-1830}

Volume 9

Issue 1 Special Issue: Eighteenth-Century Camp

Article 2

2019

\title{
Sterne's Sentimental Temptations: Sex, Sensibility, and the Uses of Camp
}

Julie Beaulieu

University of Pittsburgh, jrb107@pitt.edu

Follow this and additional works at: https://digitalcommons.usf.edu/abo

Part of the Dramatic Literature, Criticism and Theory Commons, Feminist, Gender, and Sexuality Studies Commons, and the Literature in English, British Isles Commons

\section{Recommended Citation}

Beaulieu, Julie (2019) "Sterne's Sentimental Temptations: Sex, Sensibility, and the Uses of Camp," $A B O$ : Interactive Journal for Women in the Arts, 1640-1830: Vol.9: Iss.1, Article 2.

https://doi.org/10.5038/2157-7129.9.1.1173

Available at: https://digitalcommons.usf.edu/abo/vol9/iss1/2

This Scholarship is brought to you for free and open access by Digital Commons @ University of South Florida. It has been accepted for inclusion in ABO: Interactive Journal for Women in the Arts, 1640-1830 by an authorized administrator of Digital Commons @ University of South Florida. For more information, please contact digitalcommons@usf.edu. 


\title{
Sterne's Sentimental Temptations: Sex, Sensibility, and the Uses of Camp
}

\begin{abstract}
Laurence Sterne's lack of commitment to the tenets of sentimentality in A Sentimental Journey-present in his ability to mock and praise the individual capacity to feel, and more precisely, in his satirical reading of the "cult of sensibility," the new ideological imperative to have and to showcase deep, sentimental feelings-remains as one of the central challenges for readings of the novel. To explore Sterne's portrayal of sensibility in A Sentimental Journey, I turn to camp sensibility, and the discussions that followed Susan Sontag's "Notes on Camp." Sterne's novel could be read as camp, perhaps most notably in his blending of the high and the low, but my purpose here is to raise questions about our attachments to camp sensibility, and more specifically, our attachments to camp sensibility as a gay sensibility, via Sterne's representation of bourgeois subjectivity in the novel. Queer sensibilities provide marginalized people with a collective "essence"-a shared belief in a fundamental nature that separates and elevates members of the group. In a similar way, Yorick's sensibility-and the performance of sentiment in eighteenth-century fiction more broadly-provides a new measure for class, conduct, and identity. I argue that the slow shift from blood to conduct as an index of value ushered in not only an increased demand for self-discipline but also the injunction to examine one's feelings. Sensibility-a quality that signals a keen awareness of affect that demonstrates character-shows how power functions through feelings. Sterne's representation of the sensible man's submerged sexual desire demonstrates how the cult of sensibility both defined and restrained those aspiring to meet the demands of new definitions of respectability.
\end{abstract}

\section{Keywords}

Laurence Sterne, A Sentimental Journey, camp, sensibility, class

Creative Commons License

(c) (i) (8)

This work is licensed under a Creative Commons Attribution-Noncommercial 4.0 License 
My first encounter with camp - the queer sensibility theorized by Susan Sontag and Moe Meyer, among others - was fairly remarkable. I felt emboldened by various claims about queerness, aesthetics, and our collective, queer outsider status; I found new context and value for my voice as queerness was tied to a minority yet privileged way of being and seeing. Full disclosure, what I liked best about camp sensibility was the belief that it was difficult for straight people to get. Queer sensibility, or camp, circumvented the thorny politics of essentialism by locating queer difference in epistemology and feeling, preserving without pathologizing queer difference. In fact, camp's politics of exclusion-who is in and who is not in on the joke-when read as a survival technique for queer people living under heterosexual hegemony, codes camp as a queer life hack, deepening queer attachments to these exclusions. In Camp: The Lie That Tells the Truth (1984), Philip Core claims that camp is affected by both secrets and isolation; Core writes, "There are only two things essential to camp: a secret within the personality which one ironically wishes to conceal and to exploit, and a peculiar way of seeing things, affected by spiritual isolation, but strong enough to impose itself on others" (9). Core explains further, "while camp is now often a joke or pose among gays, it is not without serious value" (9). It is a common language, a sign system for fellow feeling. Core writes, "For the outsider, society prescribes no such learnable code; for his own sanity and merely to communicate with his fellows it must be devised" (9).

And yet, what kind of logic ties sexuality to epistemology and feeling? Is this not a well-known hallmark of heterosexual hegemony, the wedding of moral or ethical sentiment to hetero-erotic desire? As Paul Kelleher persuasively argues in Making Love: Sentiment and Sexuality in Eighteenth-Century British Literature (2015), the political and social marginalization of same-sex love requires that we see hetero-erotic desire as a superior form of human contact; it must be read as more ethical, natural, and rational, and it must be the image of goodness, broadly defined. The relationship between political oppression and right or wrong ways of feeling should remind us to rethink our investment in the broader discursive project of attaching sexuality to sentiment.

These introductory comments bring me to Laurence Sterne's A Sentimental Journey through France and Italy (1768), a key text in the literary history of sex and sentiment. First, Sterne's novel provides a good-humored yet ideologically brutal portrayal of heterosexual hegemony, male license, and the privileges of rank, showing precisely how sex and feeling can be deployed to preserve, rather than to disrupt, the status quo. At the same time, Yorick, Sterne's narrator and traveler, makes routine nods to the compulsory show of sentiment, what later becomes known as the "cult of sensibility," showcasing an awareness of 
performance of the self. Yorick's camp sensibility, when read as part of a literary history of sex and sentiment, provides a lens to rethink queer investments in camp theories and methods, which I will explore. At the same time, Yorick's capacity to see the world in quotation marks, which provides a clear representation of what we might now call hetero-camp sensibility, challenges the modern link between camp and queer. I use Sterne's portrayal of Yorick's camp sensibility as an occasion to reflect on what we mean by living life without quotation marks and why we assume (through the presumption of camp as queer sensibility) that this is what straight feels like. In this way, we tie community to a set of affects and codes.

Devoney Looser's description of vanilla camp is useful here to characterize the stakes of camp that might be better understood as "Camp Lite"; on vanilla camp, Looser writes,

It is not camp that sets out to overwhelm or to deeply shock. It is a form of camp that provokes harmless, mild sexual surprise. It is safe camp-camp that might even fly under the radar, should the reader's eye not be finetuned to note it. It is safe-for-work camp.

Like vanilla camp, Sterne's camp indulges in excess, highlights the thingness of the thing (in Sentimental Journey, the performance of sexuality and class), and yet one gets the sense that this is mere play, not an urgent need to discover community via queer codes: "Camp Lite." Through these considerations, this paper proposes a set of ways of reading camp in eighteenth-century fiction as it relates to the history of sexuality and the sexual politics of feeling.

\section{Notes on Yorick's camp}

I approach this reading of Yorick's camp perspective via Sontag's "Notes on Camp," first published in 1964, as well as Moe Meyer's reading of Sontag, in which Meyer critiques Sontag's description of camp as apolitical. Meyer's "reappraisal" of camp includes the following points: "Camp is political; Camp is a gay discourse; and that Camp embodies a specifically gay cultural critique" (39). Much like eighteenth-century discourse on sensibility, camp sensibility refers to a way of seeing and feeling that some claim is only available to select individuals. On camp, Meyer writes, "all un-gay activities that have been previously accepted as 'camp,' such as Pop culture expressions, have been redefined as examples of the appropriation of gay praxis and no longer qualify as Camp as it is defined here" (39). I note this here not to determine what kind of camp Sterne's text represents - it would fall under appropriation in Meyer's terms - but to highlight 
a shared hallmark of camp and sensibility: both are preoccupied with distinctions between real and false performances of sentiment.

Because the exploration of sensibility in A Sentimental Journey ties sensibility to status and privilege, Sterne's narrative raises significant questions about the effects of attributing a certain type of knowingness to both class and sexuality. This epistemological issue-how "sensibility" produces and defines sexuality and class - guides this inquiry. My interest rests in history as a key method for reframing and rethinking our existing attachments to specific ways of knowing sexuality, class, and sensibility.

Reading Sterne's portrayal of excessive feeling as camp highlights Sterne's use of camp and allows us to see how it participates in a larger conversation about acts, identities, and performance. As sensibilities, camp and eighteenth-century sensibility share characteristics: they both identify people with a heightened receptivity that structures the way they experience the world, and this heightened sensibility is significantly shaped by class. ${ }^{1}$ While eighteenth-century understandings of sensibility unapologetically display an investment in class, camp sensibility and queer parody refer to a set of methods that seek to disrupt accepted understandings of class and sexuality.

Sontag claims that "no one who wholeheartedly shares in a given sensibility can analyze it"; and further, Sontag writes, "to name a sensibility, to draw its contours and to recount its history, requires a deep sympathy modified by repulsion" (276). These statements highlight the analytical qualifications of camp. Sterne, well known to combine sincerity with satire, offers readers a camp perspective toward sentimentality in A Sentimental Journey. Yorick's lack of commitment to the tenets of sentimentality - his tendency to mock and to praise the individual capacity to feel-is one of the central challenges for readings of the novel. Much of the text exists in the space between earnest sentiment and caricature, a space Sontag links (in the quote above) to analysis; pure, unswerving adherence to sensibility, as Sontag notes, makes analysis impossible. Sterne's reading of the cult of sensibility, the new ideological imperative to have and to showcase sensibility, is captured in the text's rendering of the sentimental traveler, Yorick.

The profound ambivalence that Yorick portrays towards the imagined sensibilities of the sentimental man - and particularly the imperative to use the language of sensibility to explain, condone, and elevate sexual longings - displays not only the attempt to veil vice with virtue, as others have noted, but also a response to the cultural expectations laid out by sensibility. Yorick longs for pleasure, a longing provoked by the simple pleasures he witnesses others enjoy with ease. What 
emerges from this longing is a critique of the dictates of sensibility that compel "sentimental" men to interpret the sensations of the body through the elevated language of feelings. More than a way of being, Yorick showcases a way of seeing, an awareness of the world, that is routinely assumed to belong to a specific class of people. What we see in Sterne, then, is an attention to the discursive fabrication of identity, a pre-Foucauldian awareness of the impact of bio-power on the intimate details of life and lifestyle.

Although Sontag suggests that this space between is essential for critique, such critique is not always in the service of deconstructing the self or the status quo. Because the source of eighteenth-century sensibility is both material and mysterious - it is seemingly visceral and it is also a quality that only some are able to feel and recognize - it retains a slipperiness that allows it to participate in the development of an understanding of bourgeois status as both inherent and cultural. Sensibility as a sensibility thus becomes impenetrable: it at once upholds systems of value that see the body as the origin of worth, and it protects itself from feigned or acculturated demonstrations of status through its obscure etiology. ${ }^{2}$ Yorick's sensibility — and the performance of sentiment in eighteenthcentury fiction more broadly_identifies feeling as a new measure for class, conduct, and identity.

Literary discourses on sensibility critiqued the existing class structure of the eighteenth century through a revision of what defines and constitutes individual worth. As Robert Markley has argued, "sentiment represents the bourgeois usurpation of and accommodation to what formerly had been considered aristocratic prerogatives" (217). In eighteenth-century literature, the space where this challenge is dramatized, the sentimental turn helps to shape the slow movement away from aristocratic models of worth and the gradual erosion of classifications that equate value with inborn and inherited traits. Sensibility helped to create an alternative system of individual worth that was founded in beliefs in the establishment and demonstration of benevolence, taste, and feeling - or the capacity to have feelings for others. Sterne's erotic representation of the shift from blood to conduct as an index of value supports Michel Foucault's claim in the History of Sexuality, Volume One that by the mid-eighteenth century the "bourgeoisie's 'blood' was its sex" (124).

Foucault's discussion of the deployment of sexuality - and more precisely, the strategic use of sexuality in the self-affirmation of the bourgeoisie - speaks to the relationship between sensibility and the establishment of an alternative model of value in the eighteenth century. As Foucault's account tells us, sexuality was created by and through scientific and authoritative discourses that legitimized 
sexuality as a "truth" of subjectivity. The creation of this sexual "truth" led to the development of a self-disciplining middle class, a class that willfully subjected itself to a set of norms and values in the interest of self-affirmation and social elevation. This process, Foucault argues, "invented a different kind of pleasure," a pleasure found in the processes of seeking out, and speaking of, sexual desires (171).

Sensibility, like sexuality, established rank, and it also justified the speaking of desires through the promise of the betterment of self and society. The cult of sensibility developed its own injunctions - the demand to feel, and to express feeling, so as to demonstrate individual worth — and these injunctions had similar benefits and pleasures as those presented by sexuality. Sensibility held out the promise of an alternative definition of value by locating worth in conduct, public displays of feeling, and goodwill, and it offered a means to explore the positive attributes of physical and often sensual feelings through literature. ${ }^{3}$ Under this new index of value, sensibility becomes a new way to illustrate class distinction and class difference. The focus on the individual and their capacity to do good, though seemingly more democratic than an inflexible, aristocratic understanding of value, recapitulates theories of inborn value as real sensibility was imagined as a physiological response to one's surroundings. Though conceptualized as something one aspires to through a determined commitment to cultivating sensibility and a willful control of the self, eighteenth-century understandings of sensibility were largely materialist, locating feeling, or the capacity to feel, in the body and its nerves. This particular formula for deducing value has a familiar effect: it authenticates the middle class while offering an illusion of a permeable class system, an illusion that superficially absolves new members of a dominant class from widespread class injustices. This absolution is furthered by public displays of sympathy for the poor performed by members of this newly recognizable class.

This challenge to aristocratic models of value is notable in sentimental fictions; significantly, Sterne's representation of the sentimental traveler clearly adheres to a model of rank that prohibits lowborn individuals from developing sensibility and thus elevating their status through the exhibition of a superior state. Put another way, sensibility is the effect of acculturated status, the evidence of difference, and the justification for differences in human value. The seemingly egalitarian measures of improvement that the discourses of sensibility provide mask how privilege shapes this exclusionary way of being, feeling, and seeing. Even as Yorick admits that travelling is for "knowledge and improvements," his status as a man of an elevated rank is never in question (16). His already established rank is key to understanding Sterne's representation of the bourgeois 
subject. Love, longing, and the capacity to feel are also central to the evaluation of subjects, showcasing the centrality of sexual politics in what we might now call class. With this context, placing Yorick in the long history of sex and sentiment creates a different perspective for our understandings of sexuality and feeling in the present.

In Sontag, there are similarly obscure origins for sensibility. In her comments on camp, Sontag makes a critical clarification: "Though I am speaking about sensibility only - and about a sensibility that, among other things, converts the serious into the frivolous - these are grave matters" (276). Our sensibilities, otherwise referred to as tastes by Sontag, are frequently understood as "mysterious attractions" that inflect our responses to people and art (276). The phrase "it's just a matter of taste" points to the presumably trivial impact of our unique and inexplicable leanings. However, Sontag writes, "taste governs every free-as opposed to rote-human response. Nothing is more decisive" (276). As prominent as taste is, camp taste, or camp sensibility, is nearly impossible to define. ${ }^{4}$ Taste, in Sontag's words, is result of a "consistent sensibility" (276).

Sontag's definition of camp sensibility brings Yorick's understanding of "humours" to mind as she defines it as similarly inscrutable, "almost, but not quite, ineffable" (276). When sensibility is definable, or systematized and recognizable through "rough tools of proof, ... it has hardened into an idea" (276). The act of defining a sensibility, for both Sontag and Sterne, is best accomplished through "jottings." Sontag writes, "The form of jottings, rather than an essay (with its claim to a linear, consecutive argument), seemed more appropriate for getting down something of this particular fugitive sensibility" (276-277). Yorick's speculations on sensibility in A Sentimental Journey are also jottings. Yorick's travel anecdotes capture feelings in an attempt to explore both the physiology of sentiment and the worldly benefits of erotic desire. Yorick is repeatedly interrupted by his own sensations, much like his creator, Sterne, who was suffering from consumption while writing his book.

But perhaps what is most camp about Sterne's text is the distance between Yorick and his experiences, a distance generated through the injunction to experience the world sentimentally. The following definition of camp from Sontag speaks to this:

Camp sees everything in quotation marks. It's not a lamp, but a 'lamp'; not a woman, but a 'woman'. To perceive Camp in objects and persons is to understand Being-as-Playing-a-Role. It is the farthest extension, in sensibility, of the metaphor of life as theater. (280) 
Further, Yorick's analysis of the relationship between sensibility and conduct exhibits an understanding of the relationship between agency and sensibility that is akin to Sontag's. When readers first meet Yorick, he has spontaneously decided to travel to France to "look into" an issue that he has learned the French more successfully manage (3). In Yorick's understanding of human action, "humours" replace taste as the mysterious cause of our individual choices, attractions, and desires. After arriving, dining, and some speculating on French habits, Yorick narrates one of his initial encounters, an exchange with the monk. He was, as he explains, "predetermined not to give [the monk] a single sous," and is attempting to account for this lack of generosity with his thoughts on our "humours," stating, "there is no regular reasoning upon the ebbs and flows of our humours; they may depend upon the same causes, for ought I know, which influence the tides themselves" (7). While invested in portraying "humours" as mysterious and unknowable, Yorick also notes the benefits of reading ourselves in this manner: "'twould oft be no discredit to us, to suppose it was so," he notes, "than have it pass altogether as my own act and deed, wherein there was so much of both" (7). Through Yorick's travels readers learn that our conduct, though strongly influenced by enigmatic bodily responses, if not fully determined by these "humours," can and should be improved by the individual.

Returning to questions of status, the paradigm of sensibility, like that of sexual identity, invites a reflection on the nature and value of the self. As the newly emerging bourgeoisie attempted to define itself against an aristocratic class accused of employing empty, performative gestures, they faced a key conundrum. Theories of sensibility claimed that conduct, and more particularly, the allegedly uncontrollable gestures, emotions, and feelings that arise from an innate sensibility, demonstrated cultural value and legitimized individuals as members of a new class. To pass as a member of the bourgeoisie - to become visible as a member of this group - individuals were required to make the inner, core aspects of their identity evident through the actions and feelings of the body without revealing these actions as performative or excessive. ${ }^{5}$ For this reason, sensibility is particularly available to queer readings.

Consider, as example, the performance of heterosexuality; failure to perform marks the subject as less real or authentic. Taken even further, mere knowledge of the need to perform interrupts the presumed sincerity or realness of heterosexual identity. Camp exists and becomes visible through excess, and this excess offers the potential for a critique of a stable, knowable self. It might be that too earnest depictions of heterosexuality, like too earnest depictions of class, always risk exposure. If sincerity must be performed, and actors must work to conceal the performance, then both risk exposure, or accidental camp - as Looser explains via 
Sontag, a "failed seriousness." The discourses of sensibility invite a similar critique, particularly as they ask readers to identify the difference between real and fake sentiment. Much like camp, it is easy to read exceedingly earnest expressions of sensibility as camp. ${ }^{6}$

Meyer's critique of Sontag challenges the evacuation of gay identity from readings of camp, drawing attention to the limits of making theoretical or conceptual links between queer camp and heterosexual excess. In "Reclaiming the Discourse of Camp," Meyer accuses Sontag of making camp "safe for public consumption" (37). According to Meyer, in Sontag's account, camp's status as a "homosexual discourse" is nearly erased (37). Consequently, camp is depoliticized and "irony, satire, burlesque and travesty" are mistakenly read as camp (37). His text is a passionate call to restore and reclaim camp, embellished with strong accusations: appropriations of camp that are not invested in gay politics and visibility are "dehumanizing"; they represent the "heterosexual/Pop colonization of gay discourse and praxis" (Meyer 445, 47). In short, Meyer seeks to correct a long history of camp appropriations, misuses he argues were enabled by Sontag's 1964 essay, and to assert the following: "Camp was and still is a solely gay discourse and that it is only as a gay cultural expression that Camp can be understood" (52). In Meyer's definition, camp is:

the total body of performative practices used to enact gay identity, with enactment defined as the production of social visibility. Gay identity is performative, discontinuous, and processually constituted by repetitive and stylized acts marked by the deployment of specific signifying codes, the sum of which I am calling Camp. (52)

I do not intend to defend or dispute Meyer; his critical call to reclaim camp raises key questions about the appropriation of camp and speaks to a wider concern about the potential risks of opening up critical categories that have historically served to combat social injustices. I draw attention to Meyer's account of the vexed history of the term camp in order to acknowledge camp's queer history and to explore the critical possibilities and shortcomings of reading literary representations of exaggerated performances of sensibility as camp, or more precisely, as queer parody. As Ersy Contogouris notes in "Neoclassicism and Camp in Sir William Hamilton's Naples," "scholars disagree as to whether camp should in fact be precisely defined or whether it should be understood as a more elusive notion." Here I argue for opening up the possibility of camp-extending it to include both the heterosexual and the non-disruptive- to explore our attachment to a more exclusionary model of camp, one that reads it as an exclusively gay epistemology. The camp "element," to use Contogouris' terms, 
expands our readings of eighteenth-century art and literary production, making queer readings possible.

The relationship that discourses of sensibility established between class, performance, and identity makes the demonstration of sensibility particularly open to queer readings. But importantly, like the term "queer," appropriations of camp have arguably diminished its critical use. To explore the risk of appropriation - or misuse - I ask the following: how do we read representations of self-reflexive ${ }^{7}$ and performative identities that use performance as a way to maintain, rather than queer, the status quo? Do exaggerated performances of identity always present queer possibilities? Should we, or how might we, contextualize performativity and parody as indicative of a shared sensibility that might be, in fact, an un-queer bourgeois tactic rather than a queer strategy?

The classification of performativity as a queer tactic masks the regular, and often flagrant, use of performance to buttress the status quo. Parody for conservative ends, if and when it might be recognized as subversive in some manifest way, must then be recognized as accidently queer. By this assessment, unintended queer readings of identity offer evidence of the instability of identity, and this proof of instability is further substantiated because it is seemingly unconscious.

In terms of class, like sexuality, a binary exists that ties status to both sincerity and performance. On one side of the binary is the self-aware, performative bourgeois individual, and on the other, the sincere and earnest rustic type. This first figure is associated with an affected relationship to class that must also appear natural so as to uphold the bourgeois critique of aristocratic airs. Whether conscious or not, bourgeois affect is marked by a need to demonstrate an interiority via taste and conduct. For this reason, it is understood as intentional, if not ostentatious. The artificiality of the bourgeoisie is brought into view through the simplicity of the laboring class in the same way that the allegedly authentic airs of the bourgeois display the artifice of the aristocracy.

Yorick's representation of the materiality of sensibility is noticeable early in the novel in his description of his servant in France, La Fleur. Attempting to excuse his use of another, Yorick agrees to a servant only after his landlord offers to procure him one. Yorick is immediately assured of La Fleur's fidelity - by his landlord's conviction and by his own observation of La Fleur's sincerity-so he accepts the landlord's offer with little knowledge of La Fleur's skills. He notes, "I shall find out his talents, quoth I, as I want them" (41). It is worth looking at the description of La Fleur at length, as the depiction exemplifies the text's representation of rank, and offers a frame for considering the novel's relationship 
to sensibility. Yorick claims,

As La Fleur went the whole tour of France and Italy with me, and will be often upon the stage, I must interest the reader a little further in his behalf, by saying, that I had never less reason to repent of the impulses which generally do determine me, than in regard to this fellow-he was a faithful, affectionate, simple soul as ever trudged after the heels of a philosopher; and notwithstanding his talents of drum-beating and spatterdash-making, which, tho' very good in themselves, happen'd to be of no great service to me, yet was I hourly recompenced by the festivity of his temper-it supplied all defects-I had a constant resource in his looks in all difficulties and distresses of my own-I was going to have added, of his too; but La Fleur was out of the reach of every thing; for whether 'twas hunger or thirst, or cold or nakedness, or watchings, or whatever stripes of ill luck La Fleur met with in our journeyings, there was no index in his physiognomy to point them out by-he was eternally the same. (43)

La Fleur's physiological and emotional consistency stands in stark contrast to Yorick's seemingly constant state of emotional flux. Yorick's body persistently reacts; a thought of another's humanity could bring a "suffusion of a finer kind upon [his] cheek" or make him "as weak as a woman" $(5,27)$. He offers these experiences without analysis, leaving it "to the few who feel to analyse" (26).

Returning to questions of performance and class, it is worth noting the ways in which Yorick's privilege in fact stabilizes class through the very parody some read as inherently disruptive. While Yorick's camp sensibility might trouble some of his readers' faith in a stable identity through the affected performance of sensibility, accepting this assessment without a critical analysis of privilege necessarily forgets that power influences who can challenge the boundaries of identity. As failed sincerity, camp is used as a tool for seeing cultural practices and values. When the masquerade fails, the performance comes into view. If the performance of cultural ideologies must always be underpinned by seriousness in order to be camp, then they might always be performed self-consciously. Yorick's performance of bourgeois pretensions offers a camp demonstration of the inherently performative nature of class, but his acute awareness of the world he travels, together with his responsiveness to his environment, in fact bolsters his identity rather than unsettles it. What Yorick's performance brings into view, then, is the utter stability of rank.

Indeed, as a queer aesthetic, camp responded to real social traumas. But the wedding of the performative to queer has encouraged us to see the awareness of 
the self as an identity that is held together only through mimetic acts as a queer awareness. While queer is recognized as a critique of bourgeois models of respectability, the awareness of performativity is also wedded to a bourgeois understanding of the self. Sterne's Yorick depicts the inherently performative nature of class, a depiction that invites us to consider the queer implications of the text. However, the text illustrates the limits of performance as a queer, or unsettling tactic by tying self-conscious activities to real sensibility.

\section{Yorick's queer feelings}

Yorick's depiction of sensibility, although hetero-erotic and in the service of a heterosexual status quo, is queer to the extent that it challenges the nature and the utility and purpose of hetero-erotic desire as well as human sexual longing more broadly; it provides a narrative of the imagined link between hetero-erotic desire and the good without relying on reproduction or the family. ${ }^{8}$ As historians of sexuality have argued, heterosexuality is a rather recent invention. If we read Yorick's articulation of pleasure - and the use value of pleasure for fostering good in society - as evidence of an already existing heterosexual ethos, we overlook the fact that Sterne's novel exists within a literary history that is responsible for creating (not simply representing) the link between hetero desire and moral feeling. The recoding of sexual longing as a solution not a problem, a trend that is widespread in erotic sentimental fiction, is part of a broader history of rethinking sexual desire. Yorick's representation of the positive results of heteroerotic longing, when read as part of this history of hetero-erotic lust, queers sex by showcasing that there is a story to tell about the development of what we now call heterosexuality.

It is precisely this in-process state that we overlook when we fail to read heteroerotic desire in historical context; as with the presumed link between heterosexuality and sincerity (or life without quotation marks), we assign a certain stability and knowingness to heterosexual identity and desire, missing the broader nexus of its construction, revision, and development. Yorick's longing represents a familiar, "queer feeling" marked by the presumed epistemological advantages of camp; more specifically, Yorick's tension is not so much queer in its vulnerability or its relation to power but in his awareness of the space between self and discourse and the awareness of self as discursive subject. The cult of sensibility structures this experience.

Much like other sentimental authors, Yorick's erotic sentimentalism is elevated by the promise it holds out - the promise that he will bring more love and generosity into the world while he is in a state of longing and feeling. Yorick 
claims that he has "been in love with one princess or another almost all my life, and I hope I shall go on so, till I die, being firmly persuaded, that if ever I do a mean action, it must be in some interval betwixt one passion and another" (44). Yorick attributes his goodness to his benevolence for all people and things, vowing to "court" or "mourn" nature as quickly as he would greet a woman (36, $37)$.

Scholars have argued that Yorick's unremitting justification of his actions-his chronic use of sentiment to describe and validate his humanity - suggests that he is fretfully attempting to establish his identity. They have also explored how this instability shapes his gender. Rebecca Gould, for example, argues that Yorick is a "male hysteric." She writes, "As a male hysteric, Yorick's consciousness and interactions with others are portrayed as simultaneously masculine and feminine" (645). Gould's analysis delivers an image of Yorick as deficient, describing his performance of masculinity as always wanting, and in fact, impotent. Because of this lack, he borrows La Fleur's "phallic power" (649). In this analysis, Yorick is represented as a helpless, insufferable figure.

In Between Men: English Literature and Male Homosocial Desire (1985), Eve Sedgwick provides an alternative reading. Sedgwick reads Yorick's "pathos" as method:

[A]lthough novels like A Sentimental Journey and the Gothic spread a glamour of familial pathos over a complicated male strategy for homosocial empowerment, they are also intricately, even appealingly candid about the worldly ties and meanings of their narrators' project. Like psychoanalysis itself: imperialism with a baby face. (65)

Sedgwick draws attention to the "ideological use of male "androgyny" by identifying Yorick as a "deft broker" of class and gender differences (72). By Sedgwick's frame, if we pity Yorick, we fall for his scheme: "the manipulative potential of Yorick's position, even when he exerts and profits by it, is presented to the reader as well as to the other characters as a form of vulnerability and helplessness" (69). Put succinctly, this is a "class/gender strategy" (74).

I want to return briefly to the conclusion of Gould's analysis where she raises a possibility; she writes, "Perhaps Yorick's dysfunction is a psychosomaticallyinduced impotence, an ideogenic disorder: Yorick does not feel that he has a phallus (male power), so his phallus ceases to function" (650). In positing the possibility that Yorick suffers from a psychosomatic disorder, Gould draws attention to the relationship between discourse and experience, and thereby offers 
a reading of Sterne's text that explores the ways in which sensibility - as a cultish, requisite, performative set of traits - ushered in a new felt experience that primarily impacted what we now call the middle class; this feeling is queer as it showcases the space between performance and self.

Elizabeth Goodhue offers a similar reading of Sterne's text, arguing that the humor of the text arises from Yorick's failure of completion, a failure that is similar to the impotency described by Gould. In her analysis of the text, she writes, "nothing is funnier about A Sentimental Journey than the way selfinterrogation and self-interruption prevent Yorick from ever managing to complete a narrative point or complete a transaction with another individual" (69). This is, as Goodhue notes, the comedy of the text, as Yorick is unable to partake in the transactions he describes because he is too preoccupied with describing the joy he might finally take from his experiences. Whereas Gould sees this as a sign of Yorick's impotence, and Goodhue describes it as comedy, the representation of Yorick's predicament - an impasse that is made visible in the text through the juxtaposition of Yorick's impotence with the simple, completely satisfying experiences of rural characters in the text - creates another possibility: the discourses of sensibility, those that authenticate Yorick's position in the order of things, contain a set of requirements that, in turn, estrange Yorick from the very experiences he longs to have. In other words, in order to appear sentimental, Yorick must deny himself the very pleasures that define him. As Goodhue argues,

[W]hen Yorick endures his painful, bitter tonic of tears again and again, we find him in the midst of attempting to exercise a kind of self-discipline that amounts to a strangely willful, even neurotic, indulgence in the denial of sweetness and pleasure. (56)

The relationship that Goodhue describes here calls to mind Foucault's analytics of power; Yorick applies the discourses of sensibility to his conduct, and this process enables and disciplines a new "personage": the man of feeling (Foucault 110).

Sensibility developed into a kind of social currency during the eighteenth century by critiquing a model of value that marked blood and lineage as the sole indicators of worth. While sensibility emerges as a way to challenge the seemingly immutable lines of value drawn by a birth-equals-worth model of rank, Sterne's representation of Yorick's persistent, seemingly neurotic need to demonstrate that he is feeling sentimentally draws attention to the relationship between discourse and subjectivity. Further, because Yorick's feelings are frequently submerged sexual longings expressed in the language of sensibility, $A$ Sentimental Journey offers an illustration of how community standards shape the 
experience and value of sexuality as it relates to feeling. Put another way, discourses of sensibility, tied as they are to both class and sexuality, structure the affective experience of identity.

Through Yorick's ambivalence, Sterne's Journey demonstrates how the cult of sensibility both defined and restrained those aspiring to meet the demands of a newly formed identity. Sterne captures the ambivalence of this compromise through Yorick's obedience to what became an obligatory way of feeling. His sense of obligation - his desire to showcase heightened feeling - comes from shame: a "sheepish inferiority" experienced in the presence of those "of a better order of being" (Sterne 22). Travel offers such an opportunity to polish individual responses, brought about by various "collisions" with others in the world, like the Paris shopkeepers who Yorick claims have, "like so many rough pebbles in a bag, ... worn down their asperities and sharp angles, and not only become round and smooth, but will receive, some of them, a polish like a brilliant"-like diamonds - via "a continual haggling with customers of all ranks and sizes from morning to night" (73).

But significantly, the polish Yorick seeks to display is different from urbanity, or what we might call the civility of a cultured man-which is to say it is distinguished from the dullness of response that comes from too many collisions of a middling sort, of a shopkeeper's sort, that renders one so "worn down" that the individual becomes "little better than the stone under your foot," as Yorick sees the husband of a beautiful shopkeeper (73). This dullness of response offers further insight into Yorick's description of La Fleur, who, having little knowledge and improvement and fewer occasions to wear down his spirits by urban experience, exhibits a similarly untouchable temper. He was, as noted, "out of the reach of every thing," by Sterne's description (43). Both the shopkeeper and La Fleur offer examples of impulses_-partially acculturated and partially constitutional - that bring Yorick's elevated state into view. The sentimental man, embodied in Yorick, suffers his responses. Unlike La Fleur, perpetually unscathed, and unlike the shopkeeper, polished to dullness, a man with sensibility, like Yorick, is governed by emotional impulses.

This is a way to navigate the competing ideas of nature and nurture, either of which could challenge what Yorick proposes as possible: the refinement of sensibility via the collisions of travel and the innate moral superiority of a specific social type. La Fleur's eternal sameness gives Yorick reason to "repent" his own "impulses," those that "determine" him (43). His ability to withstand hunger, thirst, and cold, or Yorick's impression of this capacity, justifies his lot in life. As George Rousseau has argued, "nerves fed directly into the aims of empire and 
colonialism" (17). Witnessing La Fleur dress gallantly on a Sunday, hoping to spend time with a female acquaintance, incites Yorick's sympathy for the "sons and daughters of service," but La Fleur's impulses, by Yorick's estimation, are fundamentally different (Sterne 132). Yorick, chronically distressed, is "hourly" soothed "by the festivity of [La Fleur's] temper," a temper that distinguishes the two men, negating the cultures of improvement that suggest that any man can improve his state, and accounting for their respective ranks (43). Here, Yorick establishes a difference between those with an inherent capacity for sensibility and those without it. Yorick, knowing himself of a higher order, is subject to a way of loving and feeling that La Fleur simply is not.

As Katherine Turner notes, "physical susceptibility distinguished middle-class men from the sexual rapaciousness and fondness for bloodsports of the aristocracy on the one hand, and the bestial insensitivity of the working class on the other," enabling chauvinism, but also creating an imperative that leaves Yorick weak, always about to burst into tears instead of fulfilling his desires (32). Yorick playfully mocks the simplicity and contentment that he finds in laboring men, like the man he passes along the road who is weeping over his donkey with a plainness that excites Yorick, but his own imperative - to return to a kind of love typified by the "golden age" where "Friendship and Virtue met together"leaves Yorick always outside of the experience he most desperately wants his readers to believe he feels $(53,45)$.

The study of the relationship between community standards and feeling, like the one offered in A Sentimental Journey, acknowledges that communities set standards and thereby create normative expressions of emotion and sexual desire. Whether true to their promises or not, models of sensibility pledge endless fruits: health, happiness, respectability, and spiritual salvation. Theories and methods of improvement circulating in eighteenth-century Britain result in a steady preoccupation with self-improvement. This culture of improvement influenced understandings of emotion, lending credence to the belief that one could learn to feel properly for cultural rewards. Sterne's characterization of Yorick shows the sustained effort to translate bodily urges into productive sentimental temptations, a battle that renders Yorick's desires as always inchoate-somehow better than the simple love between a man and his donkey, but always imperfectly formed. He shows, then, a compulsive self-reflection conditioned by paradigmatic models of feeling established by sensibility.

Thinking more broadly about discourse, identity, and subjectivity, Sterne's Journey allows readers to see the lived experience of a way of thinking about the construction of the self that began well before Yorick's literary travels. Faced 
with a growing self-consciousness about how one feels, Yorick seeks constant affirmation, repeatedly explaining his impulses through the language of sensibility. This process reestablishes Yorick's gentility, offering a new category for understanding and affirming the self. It also creates a new channel for sexual pleasure. In addition, the text captures a restlessness - a neurosis - that shows the compulsory side of sensibility. Perhaps Yorick indulges in love, but never without a certain ideological imperative in mind. Sterne's ambivalent representation of love, visible in Yorick's struggle to frame his bodily responses with virtuous intent, offers a glimpse of the injunctions produced by the cult of sensibility.

The conceptual connections I have made here between eighteenth-century fictions and modern theories of camp raise key questions about our attachments to theoretical formulas that have complicated histories. The history of sensibility (and affect more broadly) demonstrates the tendency to use sensibility as a justification for exclusion across a range of categories; this history brings queer deployments of feeling into question. At the same time, we must recognize that foreclosing queer feelings in others in order to establish queer sensibility in the first place - the very assumption that straight equals life without quotation marks - deeply shapes our inquiries. It obscures the processes that have naturalized hetero-erotic feelings, the very processes that queer scholarship seeks to expose.

\footnotetext{
${ }^{1}$ For more on eighteenth-century understandings of sensibility, see G. J. Barker-Benfield, The Culture of Sensibility: Sex and Society in Eighteenth-Century Britain and Janet Todd, Sensibility: An Introduction.

${ }^{2}$ For more on class, sensibility, and the body, see Roy and Dorothy Porter, In Sickness and in Health: The British Experience, 1650-1850 and George Rousseau, Nervous Acts: Essays on Literature, Culture and Sensibility.

${ }^{3}$ As Markley explains, discourses of sensibility "attempt to reconcile aristocratic systems of value based on innate worth and patrilinear inheritance to middle-class conceptions of value based on notions of individual merit and worthy deeds" (217).

${ }^{4}$ Sontag declares that sensibility is "one of the hardest things to talk about" (275). Camp is especially difficult to define because it is "esoteric," and any attempt to characterize its features is seen as a "betrayal" (275). Further, an attempt to define Camp, if too earnest, might result in the production of "a very inferior piece of Camp" (277).

${ }^{5}$ Thomas King succinctly defines this "paradox within bourgeois ideology": "On the one hand, the bourgeoisie had set themselves against upper-class spectacularity; on the other, they recognized that interiority had to be made visible if moral judgments made on the basis of character were to be legitimated" (in Meyer 24). In other words, King explains, the bourgeoisie needed "to make consciousness visible while at the same time denying the performability of the body" (in Meyer 24).

${ }^{6}$ As Sontag notes, "It's embarrassing to be solemn and treatise-like about camp. One runs the risk of having, oneself, produced a very inferior piece of camp" (277).
} 
${ }^{7}$ Freya Gowrley's discussion in this issue of "reflexive and reflective images" provides another way to frame this question.

${ }^{8}$ For more on the history of heterosexuality and moral feeling, see Paul Kelleher's Making Love. 


\section{Works Cited}

Armstrong, Nancy. Desire and Domestic Fiction: A Political History of the Novel. New York, Oxford UP, 1987.

Barker-Benfield, G. J. The Culture of Sensibility: Sex and Society in EighteenthCentury Britain. U of Chicago P, 1992.

Core, Philip. Camp: The Lie That Tells the Truth. London, Plexus, 1984.

Davidson, Jenny. Breeding: A Partial History of the Eighteenth Century. Columbia UP, 2009.

Foucault, Michel. The History of Sexuality, Vol. One. Vintage Books, 1978.

Goodhue, Elizabeth K. "When Yorick Takes His Tea; or the Commerce of Consumptive Passions in the Case of Laurence Sterne." The Journal for Early Modern Cultural Studies, vol. 6, no. 1, 2006, pp. 51-83.

Gould, Rebecca. "Sterne's Sentimental Yorick as Male Hysteric.” Studies in English Literature, 1500-1900, vol. 36, no. 3: Restoration and Eighteenth Century, 1996), pp. 641-653.

Kelleher, Paul. Making Love: Sentiment and Sexuality in Eighteenth-Century British Literature. Bucknell UP, 2015.

Markley, Robert. "Sentimentality as Polemic: Shaftesbury, Sterne, and the Theatrics of Virtue." The New Eighteenth Century: Theory, Politics, English Literature, edited by Felicity Nussbaum and Laura Brown, London, Methuen, 1987, pp. 210-230.

Meyer, Moe. An Archaeology of Posing. Macater P, 2010.

Porter, Roy, and Dorothy Porter. In Sickness and in Health: The British Experience, 1650-1850. Basil Blackwell, 1988.

Rousseau, George. Nervous Acts: Essays on Literature, Culture and Sensibility. Palgrave, 2004. 
Sedgwick, Eve Kosofsky. Between Men: English Literature and Male Homosocial Desire. Columbia UP, 1985.

Sontag, Susan. "Notes on Camp." Against Interpretation: And Other Essays, Farrar, Strauss, and Giroux, 1966, pp. 275-292.

Sterne, Laurence. A Sentimental Journey Through France and Italy. 1768. The Florida Edition of the Works of Laurence Sterne, Vol. VI, edited by Melvyn New and W. G. Day. UP of Florida, 2002.

Todd, Janet. Sensibility: An Introduction. Methuen, 1986.

Turner, Katherine. Introduction. A Sentimental Journey Through France and Italy, by Laurence Sterne, edited by Katherine Turner, Broadview, 2010, pp. 11-46. 